\title{
Research on the Innovation of the Ideological Education Method of Military Academies in the New Period
}

\author{
Hao Xu, Zhiguang Guo \\ Ordnance Engineering College, Shijiazhuang 050003, China. \\ xuh12345678@sina.com
}

\begin{abstract}
This paper according to the new period military targets of military academy students ideological education put forward higher requirements, combined with the graduate management experience, on graduate students ideological situation were to analyze and sum up and innovation problem solving strategies, in order to achieve the purpose of improve the quality of personnel training.
\end{abstract}

Keywords: Military academy graduate student; ideological education method; innovation.

\section{Introduction}

Of the party since eighteen, President Xi made a series of important instructions on the education of military universities. In the direction of military colleges, President Xi pointed out "to firmly grasp the ideological and political construction of the fundamental, the goal of strengthening the military through to the school the whole process of construction and various fields". In the Academy of management activities and ideological education is an important link, in the new period military academy graduate students is an important task for the ideological education is the guarantee of graduate students under the guidance of military target, shoulder the sacred mission entrusted by the times. However, at the present stage, the ideological education of the graduate students in military academies is old, the effect of education is not good, and the education method needs to be innovated.

\section{The Necessity of Strengthening the Ideological Education of the Graduate Students in the New Era}

\subsection{To Lay a Solid Foundation for the Study of the Ideological Foundation of the Party's Command.}

Military colleges and universities is an important base for training talents for our army. How to cultivate the quality of graduate students, especially the ideological and political quality, will affect the army's overall construction, development, and the outcome of the future war. Under the new situation, correctly guide the military academy students to set up scientific world view, outlook on life, values, establish the "dream of a strong army" of the ideals and beliefs, the training to become a listen to the party's command, political firm, firm belief, noble moral, willing to sacrifice of a new generation of military personnel, to strengthen the comprehensive construction of the armed forces, winning local wars under the condition of information has a crucial role.

\subsection{The Need to Implement the Goal of a Strong Army.}

Military objectives and reveals the consistent with the forces of the objectives and tasks of the party and the objectives and tasks, build a strong army and the prosperity of the country, the rejuvenation of the Chinese nation, people's well-being of the unity of objective law, and further clarified the important strategy position of national defense and army building in the cause of the party and the country overall. Military academies must focus effectively fulfill its mission, close to preparations for military struggle of living practice, identify the "source troops, above the troops, for responsibility positioning of forces, to graduate students' Ideological Education in the construction of national defense and the armed forces to achieve the goals down to understanding and promote, focus in the ideological field sharp and complex situation and the reality of the army, around to hold high the banner of party is in command of the fundamental and the learning goals of strengthening the 
military thought achievement and personal ideals and beliefs of tightly bound, condensed conscious thought and action, will and strength and unwavering army with Chinese characteristics.

\subsection{The Need for Training New Type of Military Personnel with High Quality.}

Stringing army troops, relying on key personnel, based on education. Military education is the main channel to improve the quality of officers and soldiers training military personnel, is the cornerstone of the development of army construction. At present, the army is not entirely meet the quality and ability of talents and carry out diversified military tasks. Ideological education as playing the main position of prison officers and ideological foundation, its core competitiveness must reflect in training to fight, win victory military personnel of a new type of function, to from a global and strategic height, fully understand the grim situation facing and shoulder the lofty mission, further enhance and strengthen the military academy students ideological education of sense of responsibility and sense of urgency.

\subsection{The Need for Strengthening the Academic Innovation Spirit of Graduate Students.}

New military reform in the world, the rapid development of our army to win the modern information war needs to continue to enhance the quality of innovative talents in the future of the status of the war has become increasingly prominent. In the implementation of the military personnel strategy project, the graduate education in the top level of our military personnel training system. According to the current situation and tasks, to improve the innovative ability of graduate students in military college has become a key part of high-quality military personnel of a new type of culture for the optimization of our army talent structure, adapt to the needs of future wars has very important significance. In the process of ideological education of the military academy students, it is necessary to use many ways, further enhance ideological education pertinence and effectiveness, innovation of ideological education methods and means, vigorously develop graduate student's innovation spirit and innovation thinking, so as to cultivate the army construction and development needs of high-quality innovative military talent to lay a solid foundation.

\section{Analysis on the Current Situation of the Graduate Student Thought in the New Period}

At this stage, the military academy graduate students generally low age, social experience is not rich, psychological maturity is not high, like to contact new things, the pursuit of new fashion, to absorb new knowledge. Expands unceasingly along with the profound social and economic reform and opening to the outside world, social thought is active unprecedentedly, all kinds of thoughts and cultures are surging, international and domestic public opinion interaction significantly enhanced, for the military academy students ideas, value orientation, behavior, etc. produced far-reaching influence, of the military academy students ideological education work put forward the new test.

\subsection{Thoughts Tend to Be Mainstream, and Value Orientation Is Diverse.}

Military academy graduate students have the characteristics of a wide range of sources, both direct reading students and cadres and students, national defense students and local students, in school and had received different levels of ideological education. Generally speaking, their thoughts are healthy, positive and upward. However, under the impact of the real society and the market economy, the value orientation of the individual graduate students is still showing a trend of diversification, the ideal and belief of the individual graduate students are fuzzy, and the social responsibility is not strong.

\subsection{Self Consciousness Is Outstanding, Collective Consciousness Is Weak.}

The graduate in achieving economic self-reliance, independence is strong, have their own interpersonal circle, have a strong sense of discernment for ideological education outside indoctrination, self consciousness is strong. Because of the national family planning policy, the only child of military graduate students accounted for a larger proportion, influenced by the family environment, the only child students think more self-centered, emphasize self. Diversity at the same time, the diversification of culture, foster the type of diversification, research direction and in some degree the military academy graduate teaching and research activity is dispersive characteristics, therefore compared with the undergraduates, their collective consciousness is relatively weak. 


\subsection{Real Demand Increases, Psychological Pressure Increases.}

According to statistics, in the psychological problems of graduate students, research and employment pressure, interpersonal barriers, emotional confusion accounted for a larger proportion. In learning research, military academy graduate school system is short, training and management of daily occupy a certain amount of time. In addition, the graduate degree awarded process more strictly, but also adds to the pressure of learning and research; distribution in the graduation, military academy graduate has a higher expectations, jobs and specialty matching degree is higher, more than graduate students at the same professional direction to that of hope, there is a certain competition; In interpersonal communication, military academy graduate circle of contacts is more complex, both from the direct management of the supervisor and team leaders, to to the brothers. At the same time, but also with the outside the barracks classmates, friends and so on maintain communication, expand the circle of communication, ideological stability susceptible; in emotional marriage, military university postgraduates have reached marriageable age, on subjective affection for, mate concept is relatively mature, but due to the closed military occupation of the particularity and the management of military academy, less opportunity for contact with the opposite sex or lover, love success rate is not high, in marital emotion also exist certain pressure.

\subsection{Fuzzy Learning Motivation, Ideal and Belief Weakening.}

Military academy graduate learning objective is no longer simply in order to knowledge obtaining, the pursuit of truth, and in a certain extent, more pragmatic, hope realize personal value of life, access to social recognition, to win more lucrative returns. The individual just to get higher degree or later in distribution and was admitted to the graduate students, lack of motivation in learning. Individual studies by network or influence others serious, outlook on life and value outlook to a certain extent the trend of utilitarian and practical direction.

\section{The Methods and Countermeasures of the Ideological Education of Military Academies in the New Period}

Strengthen under the new situation of military academy students ideological education must thoroughly implement the military objectives, adhere to the "demand oriented, in educating people as the fundamental, to the quality as the core, to reform the basic concept of power", push forward under the new situation of military academy students ideological education innovation and development.

\subsection{Play a "Research into the War" Thought.}

Military academy first name army". Military graduate students are both highly educated talent, but also a revolutionary soldier, to strengthen the awareness of the military personnel to strengthen the martial arts, and effectively fight the "research into the war" thought.

1.Soldiers in training, grasp the military force investigation practice. Use cold summer vacation, to organize research even soldier training, experience the life in the army, resulting in thinking and Thinking on more close to the reality of the army; combining with the teaching practice, research organization students to army field research, strengthen the training of practice ability, promote knowledge to the ability of the transformation of, get rid of "paper on the soldiers" and "heavy academic, light military thought.

2.To actively carry out professional practice. There are plans to arrange graduate troops engaged in various exercises and comprehensive training to improve their professional knowledge and skills and military command. The identity of the graduate students to combatants into the role, the personal experience of the drill, to effectively promote the docking of the theory and practice, the combination of classroom and battlefield.

3.Strengthen the practice of self management. According to the actual situation of the military to carry out turns Daizhi activity, let the students take the management activities of planning, organizing and directing the work, to the procedure and content of management familiar with the work, and strive to achieve by "management" to actively participate in management, turn out to be owners, the formation of "participation of all, everyone to do" good situation. 
4.Strengthen social practice. Social practice can help the students to find the best combination of theory and practice, so that the lack of the original theory can be added and deepened in practice. Through social practice can closer military academy graduate students and society, can deepen the understanding of the party's line, principles, policies and national and military conditions and customs of the, in order to further strengthen belief in following a strong army with Chinese characteristics.

\section{Create a "People-oriented" Environment}

1.Optimize the living environment and enhance the students' ability to work in Ideological education. The living environment directly affects the healthy development of the graduate student body and mind. Many military academy graduate school or management team gradually improved the entertainment facilities, to enable students to have a team with karaoke room, billiard room, table tennis room, chess and card room, and integrated comprehensive club, and in the lobby of the dormitory acquire "Junrongjing", also designated person responsible for the dormitory area health and safety, to build a graduate special bicycle shed. The entertainment and living facilities construction, to ensure the spare time graduate, music, the Clarks, effectively promote the smooth implementation of the work of ideological education.

2.Optimize the environment of public opinion, to enhance the ideological education influence. Public opinion environment has a direct impact on the long term, and strong graduate students thought and behavior. The students' team spirit is the spirit of the military academy, which reflects the public opinion environment of a small group of students. Around wind construction team, many military academy graduate students student teams to determine the "unity, dedication, study, discipline" team wind and tree upright, grasping typical, good behavior, good tendency, good examples become mainstream. To accomplish great tasks, learning scientific research achievement is outstanding and in key performance good graduate, as duty outstanding performance, actively participate in compulsory labor and ongoing contributions to engineering activities give great praise and publicity.

3.To optimize the external environment, strengthen graduate student ideological education work force foreign aid. Optimize the environment can promote the small environment construction. Note by brothers' College and the neighboring units of experience and strength, seriously find the students ideological education in the weak weak links, devote great effort to solve the existence of key and difficult problems, so as to further strengthen the self construction, promote the development of ideological education work better.

\section{Pay Attention to the Combination of Teaching and Management}

Strengthen ideological education and administrative management. Do a good job of ideological education of graduate students, to achieve the management of teaching and management, on the basis of the inspiration of consciousness, but also the need for strict administrative management. Therefore, the graduate management in conscientiously do a good job of ideological education universal, at the same time, to timely use regulations, rules and regulations and the superior instructions to regulate the behavior of students; in a timely manner to carry out rectification work style and discipline activities, focus on solve the problem of a small number of students rambling style; regular ideological situation analysis, timely and accurately master the graduate student's thought condition, and effectively grasp the initiative of education management.

\section{Conclusion}

Thinking in the management of the embodiment of the management: the management of the use of existing knowledge, experience and means to advance the development of things to make inference and judgment, with the future trends and objectives to guide the transformation of a thinking. 
Advanced thinking is an important performance of managers' initiative, and it is an important foundation for the future and scientific decision-making in the management activities. Military academy graduate management only set up the advanced thinking, can promptly seize postgraduate ideological changes of the clues, accurately grasp the development trend of graduate thought, so as to improve the scientific level of decision-making, and further enhance the timeliness of ideological education, effectiveness.

The ideological education work directly affects the quality of the training of graduate students in military academies. A careful analysis of current graduate ideological situation, combined with the actual situation of army colleges, innovation method of ideological education, training is the guarantee of high quality military personnel of a new type, to carry out ideological education of graduate students in the new period has important significance.

\section{References}

[1] Educating the Best Minds for the Knowledge Economy: Setting the Stage for Success[EB/OL].http://www.cags.ca/Portals/34/pdCTcnowledge_econoiny,2008.

[2] ACST Expert Panel on Sill .Stepping Up: Skills and Opportunities in the Knowledge Economy[EB/OL], http://acst-ccst.gc.ca/acst/skills/finalrepdocs/ acst-s, 2008.

[3] Ben David, Joseph. Centers of Learning: Britain, France, Germany, United States [M]. Mc Graw Hill, 2009.

[4] Franke, V C., Preparing for peace: Military identity, value orientations, and professional military education. 1999, Westport, CT: Praeger Publishers.

[5] Council of Graduate Schools U.S.. Findings from the 2009 CGS International Graduate Admissions Survey [J]. April 2009. 